\title{
Formação continuada para conselheiros municipais de educação e a avaliação dos planos municipais de educação
}

\author{
Continuing formation for municipals educacation counselors and avaliation of \\ municipal education plans
}

\author{
Solange Jarcem Fernandes* \\ Aureotilde Monteiro*
}

\section{Resumo}

O artigo analisa as propostas de avaliação dos planos municipais de educação elaboradas pelos conselheiros municipais de educação que participaram do curso de extensão Formação Continuada de Conselheiros Municipais do Programa Nacional de Capacitação de Conselheiros Municipais de Educação, vinculado à Secretaria de Educação Básica do Ministério da Educação e oferecido em parceria com a Universidade Federal de Mato Grosso do Sul. O curso visou a contribuir para a formação dos conselheiros e a fortalece-los como uma das instâncias de gestão democrática e de acompanhamento e avaliação das políticas públicas implementadas na área educacional nos respectivos municípios. Para este estudo, trabalhou-se com os documentos do programa, o material didático do curso e o projeto de avaliação e monitoramento elaborado pelos conselheiros, denominado de Projeto Integrador, nas suas dimensões política e de controle social. Do resultado das análises realizadas nos projetos integradores, é possível afirmar que os conselheiros apresentaram entendimento do papel e da função sociais dos conselhos municipais de educação no processo de formulação dos instrumentos de avaliação de políticas públicas e no acompanhamento do planos municipais de educação dos respectivos municípios dentro da proposta do curso de extensão, a formação com bases democráticas.

Palavras-chave: Avaliação. Conselheiros municipais de educação. Planos municipais de educação.

\section{Abstract}

\begin{abstract}
The article analyzes the avaliation proposals of Municipal Education Plans, elaborated by the Municipal Education Counselors who have attended the Continuing Education Extension Course for Municipal Counselors of the National Capacitation Program of Education Municipal Counselors, linked to the Basic Education Secretariat of brazilian Ministery of Education and offered in partnership with the Federal University of Mato Grosso do Sul. The course aimed to contribute on forming counselors and strengthen the Municipal Education Councils as one of the instances of democratic management and of monitoring and avaliation of the public policies implemented in the educational area of the respective municipalities. For this study were used the Program documents, the didactic material of the course and the avaliation and monitoring project elaborated by the Councilors called Integrator Project, in its political dimension and social control. From results of the analyzes carried out in the Integrative Projects, it was possible to affirm that the councilors presented an understanding of the social role and function of the Municipal Councils of Education in the process of formulating the instruments for avaliation of public policies and of monitoring of the municipal education plans of the respective municipalities, within the proposal of the extension course which was the training with democratic bases.
\end{abstract}

Keywords: Avaliation. Municipal education counselours. Municipal education plans.

\section{Recebido em 26/03/2018 - Aprovado em 15/06/2018 \\ http://dx.doi.org/10.5335/rep.v25i3.8575}

\footnotetext{
Doutora em Educação pela UFMS. Professora adjunta da Faed/UFMS. Atua no curso de Pedagogia e no Programa de Pós-Graduação em Educação. E-mail: solangejarcem@gmail.com

** Mestre em Educação pela UFMS. Professora do curso de Pedagogia e coordenadora do curso Pró-Conselhos da UFMS. E-mail: monteiro.ufms@gmail.com
} 


\section{Introdução}

O artigo analisa as propostas de avaliação e monitoramento dos planos municipais de educação (PMEs) elaboradas pelos conselheiros municipais de educação no processo formativo do curso de extensão Formação Continuada de Conselheiros Municipais de Educação. Esse curso estava vinculado ao Programa Nacional de Capacitação de Conselheiros Municipais de Educação (Programa Pró-Conselho) da Secretaria de Educação Básica (SEB) do Ministério de Educação (MEC) e foi oferecido em parceria com a Universidade Federal de Mato Grosso do Sul (UFMS) nos anos de 2015 e 2016. Seu objetivo era apresentar os pressupostos da gestão democrática na organização dos conselhos, considerando os conselhos municipais de educação como uma das instâncias de participação, acompanhamento e monitoramento das políticas públicas implementadas na área educacional nos respectivos municípios; também tinha caráter de formação para o exercício das funções de conselheiros municipais de educação.

O Programa Pró-Conselho teve como objetivo nesse período desenvolver uma política de democratização da gestão educacional e dos sistemas de ensino do país. A UFMS, por meio do Núcleo de Gestão Escolar do curso de Pedagogia, foi a responsável pela oferta e pela coordenação do curso em nível de extensão. No âmbito do estado de Mato Grosso do Sul, 38 municípios tinham conselhos municipais de educação na época do oferecimento do curso, e desses 26 municípios aderiram ao curso.

O material do curso foi elaborado pelo MEC em parceria com as universidades públicas e tinha como objetivo oferecer condições para que os conselhos municipais de educação pudessem, além das funções já exercidas e previstas na legislação - consultiva, deliberativa, fiscalizadora e normativa -, assumir as funções propositiva e mobilizadora, para enfrentar os desafios decorrentes da implantação da gestão democrática nos sistemas de ensino. Assim, os conselhos se constituiriam como órgão indutor e mobilizador da sociedade em relação às políticas públicas para a educação, implantadas e implementadas nos municípios. Outro fator decisivo para a proposição da formação foi a implantação do Fundo de Manutenção e Desenvolvimento da Educação Básica e de Valorização dos Profissionais da Educação (Fundeb) em janeiro de 2007, e sua legislação deixou mais clara a definição do regime de colaboração entre as esferas administrativas em relação ao oferecimento das etapas e modalidades da educação básica.

A institucionalização do curso na UFMS visou a auxiliar os municípios no estabelecimento de uma política de democratização da gestão educacional e dos sistemas de ensino, estabelecidos pela Constituição federal de 1988. Participaram da formação membros efetivos dos conselhos municipais de educação que se encon- 
travam em exercício do mandato no biênio 2015-2016. Os trabalhos desenvolvidos nesse curso pelos professores do Núcleo de Gestão do curso de Pedagogia da UFMS, campus de Campo Grande, contaram também com a participação de docentes colaboradores de outras instituições de ensino e de alunos da pós-graduação stricto sensu e lato sensu da instituição.

Dessa forma, esse processo formativo atendeu a demanda decorrente da institucionalização dos conselhos municipais de educação com base em uma formação pautada na perspectiva da gestão democrática, procurando fortalecê-los como "[...] instância de proposição, fiscalização e normalização das práticas educacionais e [...] enquanto locus de mediação entre o poder público e a sociedade" (BRASIL, 2009a), além de instrumentalizá-los politicamente para o acompanhamento e a avaliação das metas dos PMEs.

Ressalta-se que o processo de criação dos sistemas de ensino por parte dos municípios de Mato Grosso do Sul ainda se configura incipiente, pois, dos 79 municípios do estado, apenas 38 optaram pela criação do seu sistema de ensino e oficializaram os seus conselhos municipais de educação. ${ }^{1}$

Trabalhou-se, neste artigo, com os pressupostos de que os conselhos municipais de educação constituem uma das principais instâncias colegiadas para que ocorra a democratização da gestão não só nos sistemas de ensino, mas também no espaço de convivência escolar, e sua atuação deve estar pautada no acompanhamento, na proposição e na avaliação das políticas educacionais implementadas localmente. Assim, o auxílio na implementação e na avaliação das metas dos PMEs, estabelecidas para o decênio, seria uma contribuição essencial dos conselheiros cursistas para a educação do município.

A metodologia utilizada no trabalho consistiu na análise dos documentos do curso, do material didático-pedagógico disponibilizado para a formação e do Projeto Integrador elaborado pelos cursistas. Essa denominação se deve ao fato de o projeto necessitar da integração de todo o conteúdo trabalhado no curso, contextualizado dentro de uma proposta coletiva de intervenção sobre a realidade educacional do município. Dos projetos integradores elaborados, foram selecionados dez projetos para compor as análises propostas neste artigo. A escolha desse conjunto de projetos obedeceu o critério de apresentação de todos os elementos propostos na estrutura do modelo indicado para a elaboração. O artigo está dividido em duas partes: na primeira, discute-se o papel dos conselhos em vista de uma gestão voltada para as decisões coletivas e participativas, cumprindo sua função social como colegiado legalmente instituído; na segunda parte, analisa-se o instrumento de acompanhamento dos conselheiros cursistas por meio das propostas denominadas de projetos integradores, para acompanhar, monitorar e avaliar os PMEs de seus municípios. 


\section{Os conselhos municipais de educação: para além das suas funções tradicionais}

As instâncias colegiadas de participação, em geral, disseminaram e ganharam formatos institucionalizados e regulamentados a partir da década de 1990, assumindo novos papéis nos contornos das políticas públicas e sociais. Entende-se que, no caso brasileiro, esse modelo de participação se propagou a partir do momento em que se multiplicaram os canais institucionais resultantes das experiências de participação e de representação extraparlamentar no período de transição da década de 1980. A multiplicação dos canais de participação, ocorrida nesse período, deve-se ao engajamento e à mobilização da sociedade civil no momento histórico do processo de democratização do país.

Porém, estudos recentes têm indicado que o crescimento das instâncias participativas não foi igual para todos os segmentos sociais. Nas áreas em que houve forte indução do aparelho estatal, como, por exemplo, as áreas de saúde, assistência social, educação, e em áreas transversais, como as que tratam dos direitos das crianças e dos adolescentes, há indícios de uma trajetória de universalização (LAVALLE; BARONE, 2015). Nas áreas em que essa indução não foi percebida, observou-se crescimento, porém não tão significativo como nas áreas citadas.

Os conselhos de educação foram concebidos originalmente como órgãos de assessoramento técnico e, a partir da Constituição federal de 1988, assumem, ao lado da dimensão técnica, também a dimensão política. Entre outros fatores, isso se deu em função de seu caráter plural, induzido pelas demandas instituídas do princípio da gestão democrática da educação pública. Consilium - palavra latina que provém do verbo consulo/consulere -, na sua acepção mais ampla, significa ouvir algo ou alguém, submeter e deliberar de forma prudente, ponderada e com bom senso. Entretanto, tão importante quanto o significado do termo, é que ele deve ser um órgão colegiado voltado para a garantia dos direitos constitucionais de cidadania (CURY, 2006, p. 16).

A legislação básica educacional deixou efetivamente a critério dos municípios a criação dos sistemas municipais de educação e a prerrogativa de incumbir aos conselhos municipais de educação a autonomia de definir suas funções, natureza e competências. No Brasil, 84,8\% dos municípios, em 2011, contavam com conselhos municipais de educação. A distribuição deles no território nacional é desigual; a região Norte contava com apenas $65 \%$, enquanto, no Sudeste, $90 \%$ dos municípios já tinham conselhos constituídos (IBGE, 2012).

Atuando como agentes de mediação entre a sociedade civil e o poder executivo, os conselhos respondem às demandas do sistema educacional, de acordo com suas atribuições, e participam de forma pró-ativa nas discussões e nas definições das 
políticas e do planejamento educacional do município. Ao acompanhar a execução dessas políticas públicas e verificar o cumprimento da legislação, caso seja constatado(a) irregularidade ou descumprimento da legislação pelo poder público, os conselhos municipais têm a incumbência de solicitar esclarecimento dos responsáveis, denunciando aos órgãos fiscalizadores. Os conselhos também acompanham e fiscalizam os recursos para a educação no município e o cumprimento do PME, entre outras atribuições. Ainda, segundo Cury (2006), o conselho municipal de educação deve:

[...] ser um polo de audiências, análises, reflexões e estudos de políticas educacionais do seu sistema de ensino. E [...] o conselheiro será visto como um gestor cuja natureza remete ao verbo gerar e gerar é produzir o novo: um novo desenho para a educação municipal consoante os mais lídimos princípios democráticos e republicanos (2006, p. 65).

As responsabilidades de coordenar a elaboração e de executar e avaliar o PME são da Secretaria Municipal de Educação, porém cabe ao conselho municipal de educação o papel de incentivar, acompanhar e orientar todo esse processo, bem como de designar a sua representação para integrar a comissão de avaliação do PME. Sua ação permanente garante a qualidade desse processo e dos resultados finais da proposta. A partir da aprovação do PME, cabe ao conselho zelar pela sua execução e aperfeiçoar e avaliar o plano.

Modenesi, Nascimento e Souza (2014) apresentam os conselhos como órgão de gestão democrática que atua como um meio de participação popular na concretização do interesse público, pois se situam entre o Estado e a sociedade civil, têm um caráter nitidamente de ação política e aliam o saber letrado com o saber popular, por meio da representação das categorias sociais de base. No material didático-pedagógico do curso de extensão, essa definição é reafirmada, pois os conselhos são definidos por meio de visão de Estado ampliado, com a representação do governo e da sociedade civil, considerando que a sociedade civil é gestora das políticas públicas juntamente com os representantes do governo (BRASIL, 2009b, p. 10).

Os estudos a respeito, porém, desde a criação dos conselhos, têm constatado de maneira geral a falta de formação dos conselheiros para o exercício e o desempenho das funções para as quais foram nomeados. Estudos têm indicado (BONFIM, 2000; SATO et al., 2004) que os conselheiros eleitos não passaram por uma qualificação técnica, demonstrando despreparo para lidar com as normas e os procedimentos institucionais inerentes aos conselhos e às diferentes instâncias públicas.

O curso oferecido pela UFMS teve como proposta um modelo de formação no qual os conselheiros cursistas, concomitantemente a uma formação de caráter técnico, tivessem também como base formativa os princípios da gestão democrática. Esse curso também visava a instrumentalizá-los politicamente para atuar como 
protagonistas no processo democrático, uma vez que os PMEs são política pública de Estado.

Nesse processo formativo, as atividades curriculares do curso foram organizadas em cinco módulos, um caderno de oficina e um guia para os professores; e o conteúdo curricular foi dividido em três estágios: introdução, aprofundamento e integração. No primeiro estágio, foi utilizado o módulo I: educação e tecnologia. Este módulo teve por finalidade auxiliar na integração para a formação a distância, possibilitando ao conselheiro se familiarizar com a modalidade da educação a distância e com o ambiente virtual de ensino e aprendizagem.

No estágio de aprofundamento, foram trabalhados os conteúdos de formação. Foram utilizados três módulos, que trataram da concepção de gestão democrática e do papel do conselheiro como importante agente social, responsável por promover o processo da gestão democrática. Foram ainda abordadas as funções exercidas pelos conselhos e suas articulações com as políticas públicas, destacando as políticas de financiamento e a formação e a valorização dos profissionais da educação.

O terceiro estágio visou à integração do conselheiro com o conhecimento adquirido no estágio de aprofundamento, por meio da elaboração de um exercício de investigação, análise, síntese e ação. Esse exercício deveria contemplar a aplicação dos conteúdos trabalhados no decorrer do curso, levando-o a definir uma determinada situação-problema cujas propostas de resolução estariam vinculadas ao princípio da gestão democrática. Esta etapa foi denominada de elaboração do Projeto Integrador, tendo sido considerada a atividade avaliativa final do curso de extensão.

Como abordagem pedagógica, além do ambiente virtual de aprendizagem, foram utilizados os cadernos impressos denominados de módulos. Também foi realizado um seminário com o objetivo de discutir o papel dos conselhos municipais de educação e a política de avaliação do PME. Esse seminário foi realizado nos dois municípios-polo do curso, propiciando oportunidades de integração entre os conselheiros dos diferentes municípios. Esse seminário contou com a participação de professores de universidades públicas e dos sindicatos de professores do estado de Mato Grosso do Sul, para aprofundar questões referentes às metas do Plano Nacional de Educação, do Plano Estadual de Educação e dos planos municipais, que pontuaram nas falas os limites e avanços exequíveis para o decênio de implementação dos planos de educação nos municípios participantes do curso.

No bojo da Lei no 13.005/2014 (BRASIL, 2014), do Plano Nacional de Educação, após vários tensionamentos, o PNE gerou grande expectativa para a implementação de uma educação pautada nos princípios de qualidade social. E, nesse sentido, o curso Formação Continuada para Conselheiros Municipais e a proposta de construir mecanismos de avaliação das metas dos planos municipais com 0 
Projeto Integrador tiveram boa receptividade por parte dos conselheiros cursistas, pois, nesse momento, os planos expressavam o "grande pacto federativo e democrático para a educação" (DOURADO, 2017, p 17).

Segundo Gil (2013), os planos devem se constituir em documentos cuja finalidade é a de aglutinar informações necessárias às políticas educacionais para o conjunto dos entes federativos, indo além das ações pontuais de cada sistema de ensino e contribuindo para eliminar as desigualdades, mas com respeito à história e às culturas locais, sem desconsiderar a riqueza e a diversidade de suas respectivas trajetórias educacionais.

Especificamente em seu processo de elaboração, o PME, segundo Monlevade (2009), segue etapas nas quais o conselho municipal de educação se apresenta como figura importante. Após a aprovação do PME, cabe ao conselho zelar pelo seu cumprimento, fiscalizar e avaliar a fim de buscar o seu aperfeiçoamento. Ainda, para que o conselho municipal de educação possa exercer seu trabalho de forma contundente, o autor afirma que os integrantes "[...] deverão estar preparados para acessar e utilizar os indicadores socioeducacionais, para fundamentar seus pareceres, resoluções ou deliberações e indicações de estudos e projetos" (MONLEVADE, 2009, p. 95).

É nesse contexto que o planejamento no coletivo deve proporcionar respostas aos problemas enfrentados, principalmente no município, local onde as políticas públicas se efetivam. Nesse sentido, “[...] planos não devem surgir do 'além' ou de poucas cabeças, mas devem consistir numa resposta a situações e a questões identificadas socialmente como negativas ou insuficientemente equacionadas, demandando uma intervenção articulada" (GIL, 2013, p. 137).

Nessa concepção, o Projeto Integrador insere-se como proposta coletiva de intervenção articulada que demandaria acompanhamento e avaliação dos PMEs. O objetivo do projeto foi "contribuir com subsídios à atuação dos Conselheiros Municipais de Educação em realidades previamente localizadas e relevantes na garantia da educação escolar" (BRASIL, 2009c, p. 1). A base da proposta do projeto contou com três momentos distintos: a concepção, a elaboração e a aplicação do projeto.

\section{Projeto Integrador como instrumento de referência para o processo avaliativo dos planos municipais de educação}

Durante o processo formativo do curso, na elaboração do Projeto Integrador, considerado no fluxo organizacional como terceiro estágio do processo de formação, definiram-se como tema/problema o acompanhamento, o monitoramento e a avaliação dos PMEs para o período de 2015-2025. No decorrer do curso, foram estabe- 
lecidas as orientações para a sua formalização; essas orientações foram reiteradas no seminário realizado nos dois polos do curso. Esse processo de elaboração implicou a leitura e a análise dos PMEs e dos dados relativos ao contexto educacional dos respectivos municípios.

O seminário, denominado $1^{\circ}$ Seminário Pró-Conselho UFMS, foi realizado nos municípios de Campo Grande e de Ponta Porã e teve como foco a importância do conselho municipal de educação na avaliação do PME, além de retomar as orientações estabelecidas para a formalização do Projeto Integrador. Como resultado dessas discussões e da avaliação dos planos municipais, os projetos foram estruturados pelos cursistas como instrumento de referência para os conselheiros, a serem utilizados para o acompanhamento e o controle dos objetivos e metas selecionados.

Constatou-se nos projetos elaborados pelos conselheiros que os PMEs dos municípios estudados diferem pouco entre si; todos eles propõem que as metas sejam cumpridas, estipulam o tempo necessário para cumprimento no decênio e reconhecem que para isso deverá ser realizado o seu acompanhamento, e os períodos para realização das avaliações deverão ser próximos aos períodos estabelecidos no Plano Nacional de Educação. Nesse processo, seriam implementados mecanismos processuais de acompanhamento e avaliação por parte dos órgãos responsáveis pela educação do município.

Como explicitado na metodologia, neste estudo, optou-se pela análise dos projetos que atenderam ao solicitado previamente pelo curso: além da formalização como projeto, apresentassem elementos teóricos do curso relacionados à formação e aos princípios de democracia e ainda elementos relativos aos municípios, como dados educacionais e dados do contexto social. Além disso, previa-se a discussão sobre a representatividade dos conselheiros na comissão de avaliação do PME (20152025) de seus respectivos municípios.

Os projetos integradores, na sua elaboração, apresentam a seguinte estrutura: título; breve contextualização de como foi elaborado o PME de cada município; justificativas; metas dos planos e metas para avaliação e acompanhamento, considerando quais necessitariam de um esforço maior do poder público para a sua efetivação; objetivos gerais e específicos; e metodologia de trabalho para o acompanhamento das metas selecionadas.

Durante o seminário, foram retomadas as orientações sobre a necessidade da elaboração coletiva e do envolvimento de todos os membros do conselho municipal de educação nas fases necessárias para planejamento e redação do projeto e durante todo o processo de avaliação das metas.

Os conselheiros estabeleceram ainda, na metodologia, que precisariam criar estratégias para garantir de forma efetiva o monitoramento do PME. Para isso, 
na sua elaboração, o Projeto Integrador deveria oportunizar aos membros refletir sobre a necessidade de repensarem o PME e, partindo dessa reflexão, adotar mecanismos de avaliação, a fim de assegurar que o documento se configurasse em instrumento efetivo para as questões educativas do município, ou seja, se o projeto elaborado seria passível de execução, pois seria pouco válido um projeto ambicioso que não pudesse ser executado.

Nesse contexto, os conselheiros precisaram levantar dados educacionais que possibilitassem ao gestor educacional municipal, à comunidade escolar e à sociedade civil o acompanhamento periódico da execução das metas e estratégias do PME. A partir disso, o conselho passaria a subsidiar ações que assegurassem a participação coletiva dos vários segmentos da sociedade no monitoramento e na avaliação das políticas educacionais.

Foi solicitada também uma análise comparativa entre os dados apresentados pelo estado de Mato Grosso do Sul e os dados dos municípios participantes em relação aos indicadores educacionais e sociais, tendo como base os bancos de dados das secretarias municipais, do Instituto Nacional de Estudos e Pesquisas Educacionais Anísio Teixeira (Inep) e do Instituto Brasileiro de Geografia e Estatística (IBGE). A partir da análise, o grupo de conselheiros deveria elaborar uma planilha para o acompanhamento das ações realizadas pelas secretarias municipais de educação, para atingir as metas selecionadas como objeto de estudo dos projetos integradores.

De maneira geral, a meta 1 , que tratou da educação infantil, e a meta 2 , que tratou do ensino fundamental, - áreas de competência direta dos municípios - foram os focos dos projetos selecionados. Para a concretização dessas metas, estabeleceram-se objetivos, como, por exemplo, oportunizar aos membros da Comissão de Monitoramento Municipal e Avaliação do PME momentos de reflexão sobre as metas dos PMEs e garantir o direito à aprendizagem na qual o acesso e a permanência com qualidade sejam o fim proposto pelas instituições educativas.

Para o processo de monitoramento, os conselheiros estabeleceram estratégias e mecanismos de ação, procurando assegurar que esse documento se configurasse como instrumento que administrasse efetivamente as questões educativas do município. Entretanto, ressalta-se a presença de elementos que permitem inferir os impactos decorrentes da consolidação das metas, evidenciados por ações e indicadores que explicitam o acesso à escola pública, à permanência com qualidade e à ampliação da infraestrutura das redes de ensino, principalmente as relacionadas às atividades educativas pertinentes às modalidades e etapas de ensino de responsabilidade do município. 


\section{Projetos integradores - algumas observações}

$\mathrm{Na}$ análise do item justificativa dos projetos, constatou-se a compreensão dos conceitos sobre o papel dos conselheiros, trabalhados nos fundamentos teóricos do curso, quando argumentaram que o papel do conselho municipal de educação é participar na formulação e no planejamento de políticas educacionais. Nesse sentido, destaca-se um dos projetos que recorre a Gohn para explicitar o entendimento desse papel:

Os Conselhos são analisados como agentes de inovação nas políticas públicas porque, ao realizarem a mediação entre a sociedade civil organizada e os organismos governamentais, eles estão construindo uma nova esfera pública de poder e de controle social. Como tais representam forças sociais organizadas e contribuem para o fortalecimento de novos sujeitos políticos (2001, p. 31)

$\mathrm{E}$, em conformidade com esse fundamento, os projetos buscaram ressaltar a autonomia dos conselhos, considerando sua relevância social no processo democrático e o acompanhamento de forma sistemática dos PMEs.

Cabe destacar ainda, na proposta dos conselheiros, que os conselhos municipais de educação devem mobilizar os diversos segmentos da sociedade, a fim de fiscalizar como os recursos estão sendo investidos na educação do município. Alguns autores dos projetos consideram que, em relação ao PME, o estabelecimento de metas e estratégias ambiciosas não é suficiente, por si só, para garantir a efetivação dos objetivos.

[...] por isso, além de analisar processos e normas o Conselho Municipal de Educação terá outro desafio que é o de acompanhar de perto as metas e estratégias do Plano Municipal, com grande responsabilidade na execução e implementação das ações. Além [disso, caberá também a esse conselho] o respaldo na realização de projetos realizados pela Secretaria Municipal de Educação, acompanhando e cobrando sobre o que não foi e o que ainda será realizado conforme o cronograma estabelecido, a partir da elaboração e organização do Plano Municipal (UFMS, 2016, p. 8).

Com base em alguns indicadores educacionais, identificou-se, em um dos projetos, que tinha como objetivo acompanhar a meta 2 , a observação em relação à repetência e à distorção idade e ano escolar cursado na rede municipal como uma das problemáticas que os dados têm demonstrado, não sendo apenas um problema local, mas também significativo no país e no estado de Mato Grosso do Sul.

Conforme o diagnóstico apresentado no PME e da análise das estratégias para superação histórica dessa distorção no Ensino Fundamental no município, verifica-se que assim como no Brasil persiste um ciclo vicioso no sistema educacional: abandono e repetência, resultados que levam às distorções entre idade e ano escolar cursado (UFMS, 2016, p. 17). 
Nos projetos que tratam da meta 1 que pretendia universalizar, até 2016, o atendimento escolar da população de quatro e cinco anos de idade e ampliar a oferta da educação infantil, de forma a atender a $50 \%$ da população de até três anos anos, a proposta de avaliação consistiu no acompanhamento cotidiano das ações dessa meta nas leis municipais pertinentes, cobrando do poder público seu devido cumprimento e/ou a justificativa em caso da não efetivação do estabelecido no plano.

Em relação à meta 1, foram propostas as seguintes ações, assim detalhadas: 1) identificação da demanda de crianças que estão fora da creche, bem como a efetivação da matrícula de $100 \%$ das crianças do município na pré-escola, em parceria com os setores competentes; 2) participação nas discussões para a elaboração do Plano de Ações Articuladas (PAR); 3) estabelecimento de uma política de formação continuada dos profissionais da educação envolvidos com a educação infantil; 4) acompanhamento do atendimento da obrigatoriedade da escolaridade em nível superior dos docentes envolvidos; 5) reivindicação da construção e/ou da ampliação dos centros de educação infantil; 6) participação em comissões de valorização dos profissionais da educação e de técnicos administrativos; 7) estabelecimento de espaço para trocas de experiências entre os conselheiros e os demais membros da comunidade escolar; e 8) garantia de condições que contribuam na formação para a cidadania das crianças, por compreender a educação infantil como importante e a primeira etapa da educação básica.

Destaca-se também a preocupação com a formação dos profissionais da educação infantil em nível de graduação e formação continuada, estabelecendo condições e incentivos para que participem de eventos, como congressos, encontros, seminários, visando à construção do conhecimento e ao crescimento profissional.

Em relação à formação continuada, ressaltou-se a relevância da participação em cursos voltados para a formação com bases em princípios democráticos, que instrumentalizem politicamente os conselheiros no planejamento de ações de avaliação e no acompanhamento de políticas públicas. Nesse sentido, um grupo de conselheiros de um dos municípios ressaltou que o projeto os fez reconhecerem-se como pessoas de direitos, e que as proposições estabelecidas somente serão efetivadas se os membros dos colegiados forem competentes, líderes democráticos, capazes de mobilizar os sujeitos que compõem a comissão de avaliação e, acima de tudo, de contribuir para que uma gestão democrática se instale no âmbito da educação municipal.

Ainda sobre a gestão democrática nas escolas públicas e nos sistemas de ensino, identificou-se, nos projetos analisados, que a compreensão, ao menos teoricamente, aparece como tema relevante para os conselheiros no que se refere ao 
acompanhamento da educação no município, tendo a escola como espaço público de discussões, formulações e decisões coletivas:

A democratização começa no interior da escola, por meio da criação de espaços nos quais professores, funcionários, alunos, pais de alunos etc. possam discutir criticamente o cotidiano escolar. Nesse sentido, a função da escola é formar indivíduos críticos, criativos e participativos, com condições de participar criticamente do mundo do trabalho e de lutar pela democratização da educação em nosso país (UFMS, 2016, p. 25).

Constatou-se, a partir de uma análise geral de todos os projetos, que: na sua formulação, os pressupostos e objetivos propostos pelo curso foram consolidados, porém de formas distintas; e o processo avaliativo, por meio do Projeto Integrador, possibilitou uma reflexão por parte dos cursistas sobre a necessidade de avaliar políticas públicas implementadas nos municípios, mesmo considerando que os cursos de extensão têm limites de tempo e aprofundamento em relação aos temas abordados.

\section{Considerações finais}

Do resultado das análises realizadas nos projetos integradores dos municípios estudados, é possível afirmar que os conselheiros apresentaram percepção do papel e da função social dos conselhos municipais de educação no processo de formulação dos instrumentos de avaliação de políticas públicas e no acompanhamento dos PMEs dos respectivos municípios, dentro da proposta do curso de extensão, que era a de formação com bases democráticas.

Nesse sentido, atingir as metas dos PMEs (2015-2025) se configura, para os conselheiros municipais, o desafio a ser enfrentado, uma vez que os planos não são políticas de governo, mas políticas de Estado, sendo necessário para a sua efetividade o constante acompanhamento por parte da sociedade, colocando na linha de frente os conselhos municipais de educação como um braço do governo e também como braço da sociedade civil organizada.

\section{Nota}

1 Conforme o artigo 18 da Constituição federal de 1988, o município é um ente autônomo; e o artigo 211 estabelece o regime de colaboração. A Lei no 9394/1996, no artigo 11, parágrafo único, estabelece que fica a critério dos municípios criar seus sistemas de ensino ou compor com os sistemas estaduais um sistema único de educação básica. 


\section{Referências}

BONFIM, Raimundo. Sistematização 1. A atuação dos movimentos sociais na implantação e consolidação de políticas públicas. In: CARVALHO, Maria do Carmo; TEIXEIRA, Ana Claudia (Org.). Conselhos gestores de políticas públicas. São Paulo: Polis, 2000. p. 63-67.

BRASIL. Casa Civil. Lei no 13.005, de 25 de junho de 2014. Aprova o Plano Nacional de Educação (PNE) e dá outras providências. Brasília, 2014. Disponível em: <http://www.planalto.gov.br/ ccivil_03/_Ato2011-2014/2014/Lei/L13005.htm> Acesso: jan. 2018.

Ministério da Educação. Conselho Municipal e suas articulações com as políticas públicas. Brasília: MEC/SEB, Universidade Federal de Santa Catarina, 2009a. (Formação Continuada de Conselheiros Municipais de Educação; 3).

Concepção, Estrutura e Funcionamento: caderno 1 o contexto da atuação, natureza e organização dos conselhos municipais de educação. Brasília: MEC/SEB, Universidade Federal de Santa Catarina, 2009b. (Formação Continuada de Conselheiros Municipais de Educação; 2).

Projeto Integrador. Brasília: MEC/SEB, Universidade Federal de Santa Catarina, 2009c. (Formação Continuada de Conselheiros Municipais de Educação; 5).

CURY, Carlos Roberto Jamil. Conselhos de Educação: fundamentos e funções. Revista Brasileira de Política e Administração da Educação, Goiânia, v. 22, n. 1, p. 41-67, jan/jun. 2006. Disponível em: <http://see.ufrgs.br/rbpae/article/viewFile/18721/10944>. Acesso em: 24 fev. 2017.

DOURADO, Luiz Fernandes. Plano Nacional de Educação: o epicentro das políticas de Estado para a educação brasileira. Goiânia: Imprensa Universitária/Anpae, 2017.

GIL, Juca. Planos educacionais: entre a prioridade e a descrença. In: SOUZA, Ângelo Ricardo de; GOUVEIA, Andreia Barbosa; TAVARES, Taís Moura (Org.). Políticas educacionais: conceitos e debates. Curitiba: Appris, 2013. p. 133-162.

GOHN, Maria da Gloria. Conselhos gestores e participação sociopolítica. São Paulo: Cortez, 2001.

IBGE. Pesquisa de informações básicas municipais. Perfil dos municípios brasileiros 2011. Rio de Janeiro: IBGE, 2012. Disponível em: <http://ibge.gov.br/munic>. Acesso em: 15 fev. 2015.

LAVALLE, Adrian Gurza; BARONE, Leonardo Sangali. Conselhos, associações e desigualdade. In: ARRETCHE, Marta (Org.). Trajetórias das desigualdades: como o Brasil mudou nos últimos cinquenta anos. São Paulo: Editora Unesp; CEM; 2015. p. 51-76.

MODENESI, Thiago Vasconcelos; NASCIMENTO, Edvaldo Francisco do; SOUZA, Edilson Fernandes. Os conselhos municipais de educação: um espaço de exercício da cidadania? In: ANPAE/CONGRESSO IBERO AMERICANO, IV., 2014, Porto. Anais eletrônico... Porto, 2014. Não paginado. Disponível em: <http://www.anpae.org.br/IBERO_AMERICANO_IV/ Comunicação?ThiagoModenesi_GT1_integral.pdf.>. Acesso em: 24 ago. 2016.

MONLEVADE, João Antônio Cabral de. Plano municipal de educação. In: BRASIL. Conselho municipal e as políticas públicas. Brasília: MEC/SEB; Universidade Federal de Santa Catarina, 2009. (Formação Continuada de Conselheiros Municipais de Educação; 3). 
SATO, Wanda Nascimento dos Santos et al. Formação de conselheiros para a efetivação da participação e controle social no sistema único de saúde: análise de uma experiência. In: CONGRESSO BRASILEIRO DE EXTENSÃO UNIVERSITÁRIA, 2., 2004, Belo Horizonte. Anais... Belo Horizonte, 2004. Não paginado. Disponível em: <https://www.ufmg.br/congrext/Saude/Saude94. pdf>. Acesso em: 20 dez. 2017.

UFMS. Curso de formação continuada de conselheiros municipais de educação. Projeto Integrador. Campo Grande, 2016. (Mimeografado). 